\title{
BIBLIONLINE: NOVO TEMPO, NOVA PERIODICIDADE
}

\author{
Marynice de M. M. Autran \\ Editor de Biblionline \\ marynice.autra@gmail.com
}

Em virtude da demanda de artigos, Biblionline inicia, a partir do volume 13 com nova periodicidade, passando de quadrimestral para trimestral. Decidimos fazer essa alteração por duas razões: a demanda de submissões e o respeito aos autores, que realizam as submissões e ficam aguardando, quase que indefinidamente, a publicação de seus artigos. Dessa forma, esperamos que a nova periodicidade estimule os interessados a submeter sua produção e vê-la publicada com maior rapidez.

Sendo Biblionline um periódico de acesso aberto, decidimos, de agora em diante, colocar em todos os artigos o símbolo da licença Criative Commons, reforçando a política do acesso livre e imediato ao seu conteúdo, seguindo, assim, o princípio de disponibilizar gratuitamente o conhecimento científico, proporcionando maior democratização do conhecimento produzido.

Neste número publicamos 12 artigos, sendo seis Artigos de Revisão, os quais abordam as mais variadas temáticas, quais sejam: o paradigma social como paradigma emergente na ciência da informação; as potencialidades informacionais e documentais dos videogames e as iniciativas de preservação dos jogos eletrônicos; a produção científica sobre empreendedorismo criativo no que tange à Indústria Criativa, a fim de estabelecer a melhor nomenclatura para uso em estudos relacionados ao tema; a biblioterapia como um método de amenizar ou diminuir os sintomas do transtorno de ansiedade; as práticas profissionais advindas da Ciência da informação e sua contribuição com as profissões da informação, mostrando a concepção técnica e humanista inerentes à Ciência da Informação; a reflexão sobre a concepção de ciência à luz dos estudos bakhtinianos para a Arquivologia, assumindo uma postura de cooperação entre as áreas interdisciplinares.

Seguindo a diversidade temática, apresentamos cinco Relatos de Pesquisa, que fazem uma incursão sobre: o uso das bases de dados existentes na Universidade Federal de Santa Maria (UFSM), Campus Frederico Westphalen, assim como as dificuldades encontradas pelos usuários quando de seu uso; a missão de transcendência das bibliotecas, no que se refere ao fomento à leitura e apresenta o Projeto Biblioteca Transcol, demonstrando a oferta de material informacional em terminais rodoviários de grande circulação e disponíveis aos usuários que utilizam o sistema de transporte urbano da região metropolitana de Vitória, Espírito Santo; os elementos que caracterizam os serviços de referência virtual ofertados por bibliotecas nacionais e internacionais e aponta as diferenças existentes entre os termos "biblioteca eletrônica", "biblioteca digital" e 
"biblioteca virtual" e analisa os serviços de referência virtual ofertados por cinco bibliotecas: a (i) Biblioteca Nacional de España; a (ii) Bibliothèque nationale de France; a (iii) University of Illinois at Chicago Library; a (iv) Biblioteca Nacional do Brasil; e a (v) Biblioteca de Ciências Jurídicas da Universidade Federal do Paraná; a presença dos paradigmas da Biblioteconomia e Ciência da Informação em uma biblioteca universitária e verifica qual deles mais se destaca, constatando que os principais paradigmas identificados estão relacionados com a área da Biblioteconomia, visto ser uma instituição voltada essencialmente ao acervo, suporte e processo técnico; analisa o Curso de Especialização em Cultura e Arte Barroca (CECAB), da Universidade Federal de Ouro Preto, fundamentando-se em três pilares: a questão conceitual de Patrimônio e Cultura Barroca, fundamental para o entendimento do objeto da pesquisa, a constituição da Memória, enquanto espaço de sedimentação do saber e a Ciência da Informação, como suporte para a construção e interlocução das narrativas de memória.

Na seção Relatos de Experiência, o único artigo descreve o trabalho desenvolvido no arquivo do Centro de Documentação do IPHAN - PB (CDOC/IPHAN-PB), no qual foi realizada a gestão documental no acervo, com vistas à organização, classificação, descrição e inserção em banco de dados da documentação produzida pelo Setor Técnico da Superintendência do IPHANPB.

Por fim, na seção Resumos de Monografias, constam os resumos de cinco trabalhos de conclusão de curso, sendo quatro autores concluintes do curso de biblioteconomia da UFPB e um da Universidade Federal do Piaú́.

Desejamos, assim, aos nossos colaboradores e leitores, uma boa leitura. 